\title{
Letter to the editor: \\ Cerebral salt wasting syndrome following neurosurgical intervention in tuberculous meningitis
}

\author{
Amit Agrawal \\ Professor of Neurosurgery, Department of Neurosurgery, MM Institute of Medical Sciences \& \\ Research, Mullana (Ambala), India
}

\section{Dear Sir,}

Although rare but CSWS can develop in patients with hydrocephalus, cerebral infarction, tuberculous meningitis and can also complicate the postoperative course of surgery for brain tumors or for severe head injury. $(1,2,3)$ The pathogenesis of CSWS is still not completely understood and it has been proposed that following acute insult sympathetic responses as well as some natriuretic factors play a role in the genesis of this syndrome. $(4,5)$ Many time it is difficult to identify whether the CSWS occurred due to tuberculous meningitis per se or due to the neurosurgical intervention which was done on the day of admission. (1) We need to be aware of this potentially treatable complication, however the occurrence of the CSWS in the present cases probably can be the manifestation of complication of tubercular meningitis (basal arteritis leading to ischemic injury to the brain) rather than the complication of neurosurgical intervention.

\section{Correspondence}

Dr. Amit Agrawal

Professor of Neurosurgery

MM Institute of Medical Sciences \& Research
Mullana (Ambala)

PIN- 133203

Haryana, India.

Phone: +91-01731-274475

Fax: +91-01731-274375

Email:dramitagrawal@gmail.com

dramit_in@yahoo.com

\section{References}

1. Nagotkar L, Shanbag P, Dasarwar N. Cerebral Salt Wasting Syndrome Following Neurosurgical Intervention in Tuberculous Meningitis. Indian Pediatrics 2008;45:598-601.

2. Jiménez R, Casado-Flores J, Nieto M, García-Teresa MA. Cerebral salt wasting syndrome in children with acute central nervous system injury. Pediatr Neurol. 2006;35(4):261-3.

3. Ravishankar B, Mangala, Prakash GK, Shetty KJ, Ballal HS. Cerebral salt wasting syndrome in a patient with tuberculous meningitis. J Assoc Physicians India. 2006;54:403-4.

4. Cerdà-Esteve M, Cuadrado-Godia E, Chillaron JJ, Pont-Sunyer C, Cucurella G, Fernández M, Goday A, Cano-Pérez JF, Rodríguez-Campello A, Roquer J. Cerebral salt wasting syndrome: review. Eur J Intern Med. 2008 Jun;19(4):249-54.

5. Isotani E, Suzuki R, Tomita K, et al. Alterations in plasma concentrations of natriuretic peptides and antidiuretic hormone after sub-arachnoid haemorrhage. Stroke 1994;25:2198-203.

6. Dass R, Nagaraj R, Murlidharan J, Singhi S. Hyponatraemia and hypovolemic shock with tuberculous meningitis. Indian J Pediatr. 2003;70(12):995-7. 